\title{
ENCONTRO DE SABERES NA UNIVERSIDADE FEDERAL DO RIO DE JANEIRO: UMA EXPERIÊNCIA COM MESTRES E MESTRAS GUARANI MBYA
}

\author{
SAMIRA LIMA DA COSTA ${ }^{1}$ \\ ELEONORA GABRIEL ${ }^{2}$ \\ DANIEL RENAUD CAMARGO 3 \\ KAREN JOYCE LYRIO ARAGÃO ${ }^{4}$ \\ SANDRA BENITES 5
}

\begin{abstract}
RESUMO
Neste trabalho refletimos sobre a experiência com a primeira turma da disciplina Encontro de Saberes ofertada na Universidade Federal do Rio de Janeiro (UFRJ), que foi pensada em uma parceria com mestres indígenas do povo Guarani. Tal disciplina foi realizada no segundo semestre do ano de 2019, contou com 21 estudantes de cursos de graduação e pós-graduação, e teve como convidados um mestre e uma mestra e suas aprendizes, todos da aldeia Guarani Mbya Ara Howy, em Maricá (RJ). A experiência oportunizou espaços de trocas, produções colaborativas e complementares entre os conhecimentos guaranis e acadêmicos. As análises apontam para importantes reflexões acerca da universidade, possibilitando tanto a (auto)crítica às durezas da atual estrutura acadêmica como 0 acesso a uma outra versão da história de nosso país, e de nossa própria história.
\end{abstract}

Palavras-chave

Encontro de Saberes; Diálogos Interepistêmicos; Interculturalidade; Guarani; Saberes Tradicionais.

\section{MEETING OF KNOWLEDGE AT THE FEDERAL UNIVERSITY OF RIO DE JANEIRO:AN EXPERIENCE WITH GUARANI MBYA MASTERS}

\begin{abstract}
In this work we reflect on the experience with the first class of the discipline Meeting of Knowledge offered at the Federal University of Rio de Janeiro (UFRJ), which was thought in a partnership with indigenous masters from the Guarani people. The discipline happened in the second half of 2019 counting with 21 undergraduate and graduate students, and had as guests two masters and their apprentices, all from the Guarani Mbya Ara Howy village in Maricá (RJ). The experience brought up opportunities for exchanges and collaborative and
\end{abstract}

\footnotetext{
${ }^{1}$ Professora Associada II, Departamento de Terapia Ocupacional/Faculdade de Medicina e PPG Psicossociologia de Comunidades e Ecologia Social - EICOS/ Instituto de Psicologia da Universidade Federal do Rio de Janeiro.
}

${ }^{2}$ Docente associada da Escola de Educação Física e do Desporto, Universidade Federal do Rio de Janeiro.

${ }^{3}$ Doutorando do PPG Psicossociologia de Comunidades e Ecologia Social - EICOS, Universidade Federal do Rio de Janeiro.

${ }^{4}$ Doutoranda do PPG Psicossociologia de Comunidades e Ecologia Social - EICOS, Universidade Federal do Rio de Janeiro.

${ }^{5}$ Doutoranda do PPG em Antropologia Social do Museu Nacional, Universidade Federal do Rio de Janeiro. 
complementary productions between the Guarani and the academic knowledge. The analyses point out to important reflections about the university, enabling both a (self)criticism about the hardness of the current academic structure, and access to another version of the history of our country, and of our own history.

\author{
KEYWORDS \\ Meeting of Knowledge; Interepistemic Dialogues; Interculturality; Guarani; \\ Traditional Knowledge.
}

\title{
RENCONTRE DES CONNAISSANCES À L'UNIVERSITÉ FÉDÉRALE DE RIO DE JANEIRO: UNE EXPÉRIENCE AVEC LES MASTERS GUARANI MBYA
}

\begin{abstract}
RÉSUMÉ
Dans ce travail, nous réfléchissons à l'expérience avec la première classe de la réunion disciplinaire du savoir offerte à l'Université fédérale de Rio de Janeiro (UFRJ), qui a été pensé dans un partenariat avec les maîtres indigènes du peuple Guarani. Cette discipline a eu lieu au second semestre 2019; avait 21 étudiants de premier cycle et des cycles supérieurs; et avait comme invités deux maîtres et ses apprentis, tous du village de Guarani Mbya Ara Howy, à Maricá (RJ). L'expérience dispose d'espaces opportunistes pour les échanges, les productions collaboratives et complémentaires entre Guarani et les connaissances académiques. Les analyses soulignent d'importantes réflexions sur l'université, permettant à la fois la critique(auto) de la dureté de la structure académique actuelle et l'accès à une autre version de l'histoire de notre pays, et de notre propre histoire.
\end{abstract}

\section{MOTS-CLÉS}

Réunion de connaissances; Dialogues interépistémiques; Interculturalité; Guarani; Connaissances traditionnelles.

\section{ENCUENTRO DE CONOCIMIENTOS EN LA UNIVERSIDAD FEDERAL DE RÍO DE JANEIRO: UNA EXPERIENCIA CON MAESTROS GUARANÍMBYA}

\begin{abstract}
RESUMEN
En este trabajo reflexionamos sobre la experiencia con la primera clase de la disciplina encuentro de conocimiento ofrecido en la Universidad Federal de Río de Janeiro (UFRJ), que se pensó en una asociación con maestros indígenas del pueblo guaraní. Esta disciplina se llevó a cabo en el segundo semestre de 2019; tenía 21 estudiantes de pregrado y posgrado; y tuvo como invitados os maestros y sus aprendices, todos de la aldea guaraní Mbya Ara Howy, en Maricá (RJ). La experiencia cuenta con espacios oportunistas para intercambios, producciones colaborativas y complementarias entre conocimientos guaraníes y académicos. Los análisis apuntan a importantes reflexiones sobre la universidad, permitiendo tanto la (auto)crítica de la dureza de la estructura académica actual como el acceso a otra versión de la historia de nuestro país, y de nuestra propia historia.
\end{abstract}

\section{Palabras Clave}

Encuentro de conocimientos; Diálogos interepistémicos; Interculturalidad; Guaraní; Conocimiento tradicional. 


\section{INTRODUÇÃO}

O presente artigo tem por objetivo apresentar e tecer reflexões acerca da inclusão de mestras e mestres de saberes tradicionais na docência do ensino superior, tomando como base a experiência de implantação do Encontro de Saberes na Universidade Federal do Rio de Janeiro (UFRJ). O projeto faz parte da pesquisa "A Visão dos Mestres e os Possíveis da Universidade Pluriepistêmica: Tradição, Território e Ocupação", e compõe a rede do Encontro de Saberes, um projeto com sede no Instituto Nacional de Ciência e Tecnologia da Inclusão no Ensino Superior e na Pesquisa (INCTI-UnB). Esta iniciativa vem responder a uma demanda reprimida em nossas escolas e em nossa história: a inclusão de mestres e mestras de saberes dos povos originários e comunidades tradicionais do Brasil, como docentes no ensino superior. O projeto promove encontros interculturais e propõe a produção de conhecimentos a partir de diferentes cosmovisões, assumindo uma posição ético-política de descolonização da lógica hegemônica das universidades ocidentais, edificadas em torno da égide da colonialidade do saber, e da consequente negação dos saberes não nortecentrados.

O Encontro de Saberes vem responder ao artigo 26-A, da Lei 11.645 de março de 2008, que se refere:

"...[A] obrigatoriedade nos estabelecimentos de ensino fundamental e de ensino médio, públicos e privados, do estudo da história e cultura afro-brasileira e indígena, incluindo no conteúdo programático diversos aspectos da história e da cultura no âmbito de todo o currículo escolar" (BRASIL, 2008).

Neste contexto, as universidades são responsáveis pela formação de todos os profissionais educadores, que, por sua vez, têm o compromisso de fazer valer tais ações.

Seguindo nesta direção, desde 1987 a Companhia Folclórica do Rio-UFRJ tem trazido para a cena acadêmica os saberes tradicionais e seus representantes, inicialmente como extensão. Em 2014, a coordenadora deste projeto começou uma aproximação com o Encontro de Saberes, projeto da UnB que vinha sendo incorporado por outras universidades, trazendo também para o ensino os conhecimentos tradicionais. Em outra via, mas convergindo, a partir de 2006 o projeto Sentidos de Comunidade de Povos Tradicionais teve início em Vitória (ES), e em 2015 chegou à Universidade Federal do Rio de Janeiro (UFRJ). Este foi o primeiro Programa de Ensino, Pesquisa e Extensão voltado exclusivamente рага saberes de povos e comunidades tradicionais, sob o título de Programa Institucional Saberes e Ocupações Tradicionais. Sua coordenadora, durante os anos de 2017 e 2018, participou da implantação do Encontro de Saberes (da UnB) na UFF, fazendo disso parte de seu pósdoutorado. Em 2017 as duas coordenadoras destas ações extensionistas - Cia Folclórica e Saberes e Ocupações Tradicionais - se uniram com o objetivo de implantar o projeto Encontro de Saberes na UFRJ. Em 2018 foi aprovada a criação da disciplina de graduação 
"Saberes e Ocupações Tradicionais: Encontro de Saberes" na Faculdade de Medicina, podendo receber estudantes de diversos cursos da universidade. Ainda em 2018, as duas docentes participaram da criação do Grupo de Trabalho Ancestralidades em Rede, da Escola de Educação Física e Desportos (EEFD). Este contou com a participação de diversas instituições de ensino, em cujo âmbito, entre outros objetivos, passou a ser gestada a possibilidade do Encontro de Saberes na UFRJ.

A partir destas articulações, no início de 2019 a Universidade Federal do Rio de Janeiro passou a compor a rede de universidades que vêm desenvolvendo o Encontro de Saberes. Com apoio do INCTI-UnB, trouxe para a disciplina de Antropologia da graduação em Terapia Ocupacional e para a aula inaugural do Programa de Pós-Graduação em Psicossociologia de Comunidades e Ecologia Social a senhora Maria Muniz, mestra dos saberes da cura Tupinambá. No segundo semestre de 2019, o professor José Jorge de Carvalho, coordenador do INCTI-UnB e idealizador do Projeto Encontro de Saberes, fez uma aula inaugural que, pela primeira vez, se constituiu em um evento inter-programas e interuniversidades, incluindo diversos programas de pós-graduação da UFRJ, da UFF ${ }^{6}$ e da UNIRIO $^{7}$. Ainda neste mesmo semestre, com o protagonismo do GT Ancestralidades em Rede e da Pró Reitoria de Extensão, a UFRJ iniciou a elaboração de termo de colaboração com o INCTI da UnB. Paralelamente, esta universidade constituía um grupo de docentes e gestores - representantes de cursos de graduação, pós graduação e pró reitorias - dedicado a gerar um plano de trabalho para os próximos anos, considerando a criação de disciplinas de graduação e pós graduação; ampliação das ações extensionistas de caráter participativo; incentivo a pesquisas colaborativas com pesquisadoras/es mestras/es de tradições ou seus aprendizes; e o reconhecimento acadêmico dos saberes tradicionais e seus/suas mestres/as por meio da titulação por Notório Saber.

Paralelo a este grupo de trabalho, a UFRJ teve a primeira edição da disciplina Encontro de Saberes, organizada pelas duas docentes já mencionadas. Para esta primeira edição, a equipe contou com a colaboração de um professor da UFF - onde o Encontro de Saberes já acontecia há três anos. Teve como docentes convidados a mestra xejary ${ }^{\beta}$ Catarina Vilhalva e o mestre xeramõi ${ }^{9}$ Felix Karaí, da aldeia Guarani Mbya Ara Howy, de Maricá. Duas netas e uma filha os acompanharam nas aulas, além de terem como professora assistente a

\footnotetext{
${ }^{6}$ Universidade Federal Fluminense.

${ }^{7}$ Universidade Federal do Estado do Rio de Janeiro.

${ }^{8}$ Nossa avó, ou mestra, em guarani.

${ }^{9}$ Nosso avô, mestre, em guarani.
} 
doutoranda do PPGAS ${ }^{10}$-UFRJ, Sandra Benites, Guarani Nhandewa conhecida da família Guarani convidada, e co-autora do presente texto.

\section{SOBRE A (NOSSA) UNIVERSIDADE E SEUS PROCESSOS DE PRODUÇÃO DE SABERES}

Atualmente a Universidade enquanto instituição se vê diante da necessidade e da possibilidade de elaborar novas perguntas, novos caminhos, novos referenciais. E é nesse possivel que se colocam os saberes populares e tradicionais: como novos. Novos para a academia, ainda que mais antigos do que ela. Essa é uma contradição inerente ao processo de exclusão de conhecimentos antigos e sua "redescoberta". Os marcos e as marcas disciplinares da exclusão de tantos saberes em nossa academia ressoam por seus corredores e se repetem em nossos corpos como um sussurro quase imperceptível; a academia se acostumou com essa exclusão. Trazê-los para dentro da universidade, portanto, não é escolha fácil. Deixar de fazê-lo, por outro lado, é impraticável. Neste sentido, concordamos que:

"Propor uma inovação nas áreas de humanidades e ciências sociais na América Latina significa questionar um cânone acadêmico marcado pela rigidez das fronteiras disciplinares e por uma atitude cronicamente eurocêntrica, que privilegia os saberes da ciência ocidental moderna e exclui inteiramente os saberes criados e reproduzidos no interior de milhares de comunidades e grupos étnicos do nosso continente" (CARVALHO; ÁGUAS, 2015, p. 1018).

Esta universidade brasileira é parte do legado do projeto colonial, que tinha como um de seus intentos sustentar uma lógica moderna, racional e eurocentrada de produção de conhecimentos - uma concepção que, em seu embrião, já assumia uma separação radical entre oralidade e escrita. Nesta universidade moldada pela lógica colonial, portanto, a escrita assumiu uma centralidade e tornou-se o modelo principal para a produção de conhecimentos, enquanto a oralidade, apesar de não ter sido eliminada (COSTA; CARVALHO, 2020), passou a uma posição de subalternidade com relação a palavra escrita. Ou seja, nas universidades a oralidade só mantém sua legitimidade quando é passível de ser escrita, registrada, documentada, gravada.

Quanto a esta cisão hierarquizante entre escrita e oralidade tão comum nas sociedades modernas, Hampaté Bá (2010, p. 168) questiona "Não faz a oralidade nascer a escrita, tanto no decorrer dos séculos como no próprio indivíduo?".

A universidade brasileira e suas produções, entretanto, não estão aprisionadas necessariamente a este modelo conservador e grafocêntrico. Muitas resistências têm sido produzidas nas universidades, que aos poucos reconhecem seus lugares de produção de conhecimentos, inclusive sobre si mesmas. Carvalho e Águas (2015, p. 1023) assumem que se

\footnotetext{
${ }^{10}$ Programa de Pós-Graduação em Antropologia Social.
} 
trata de uma separação "artificial, incompleta e obviamente fetichizada negativamente por uma ideologia iluminista datada, hegemônica em nossas universidades", e completam afirmando que:

\begin{abstract}
"Um dos temas-chave referentes à ruptura acadêmica com o eurocentrismo promovida pelo Encontro de Saberes é a possibilidade de aproximação entre duas posturas que se tornaram antípodas em nossas universidades marcadas por um eurocentrismo periférico: a escrita e a oralidade. A nossa escrita científica está hipertrofiada, enquanto a oralidade está quase inteiramente atrofiada, e as duas modalidades de transmissão foram separadas artificialmente, séculos atrás, a um preço muito alto para ambas" (p. 1023).
\end{abstract}

Assim, neste artigo apontamos uma reflexão acerca da inclusão de mestres e mestras de saberes tradicionais no ambiente acadêmico, entendendo que a universidade se constitui enquanto um centro de produção de conhecimentos, em sua maioria de modo monocultural e monoepistêmico, estruturado em torno de uma lógica norte-euro-centrada.

Com isso, partimos de uma crítica a este modelo hegemônico por entendermos que, por uma questão de justiça social e epistêmica, tal concepção não cabe em um país com a diversidade cultural do Brasil. Destacamos, portanto, a necessidade de uma abertura das portas deste espaço para outras culturas, com suas diversas epistemologias, saberes e concepções de mundo. Afinal, como diria o mestre Paulo Freire (1987), "não há saber mais ou saber menos, há saberes diferentes" (p. 68). Deste modo, admitimos a pluralidade dos saberes, de culturas e de modos de ensinar como um imperativo ético que se postula a partir do reconhecimento da heterogeneidade de conhecimentos existentes.

\title{
A DISCIPLINA: ENCONTRO ENTRE CAMPOS, EXPERIÊNCIAS DE LÁ E DE CÁ
}

As aulas da primeira turma da disciplina Encontro de Saberes da UFRJ tiveram como foco diferentes questões relativas à cultura, história e aos saberes guarani, incluindo aspectos das ocupações tradicionais, tais como artesanatos, alimentação, língua, cosmologias e saberes ambientais. Englobaram também ensinamentos a respeito da agricultura tradicional indígena e elementos da convivência com a natureza, considerando sua insepabilidade de Nhander ${ }^{11}$, abarcando, por exemplo, os cantos e orações. Além disso, tais encontros também promoviam debates e experiências sobre o Nhanderekó ${ }^{12}$ (BENITES, 2018) e suas intersecções, convergências e/ou distanciamentos com relação aos conhecimentos acadêmicos até então estudados pelos participantes.

\footnotetext{
${ }^{11} \mathrm{O}$ criador do mundo e de todas as coisas, em Guarani.

${ }^{12}$ Aspecto central da cultura Guarani que pode ser entendido como "Nosso modo de ser" ou "modo de vida", em Guarani.
} 
A disciplina Encontro de Saberes na UFRJ, apesar de ter sido ofertada como optativa e ter sido aberta a diferentes cursos, tanto de graduação como de pós-graduação, teve predominância de inscritos dos cursos de graduação em Terapia Ocupacional (Faculdade de Medicina) e de pós-graduação em Psicossociologia de Comunidades e Ecologia Social (Instituto de Psicologia). Ao todo, se matricularam na disciplina 14 estudantes de graduação, provenientes dos cursos de Artes, Biologia, Educação Física e Terapia Ocupacional; bem como 7 estudantes de pós-graduação, sendo todos do programa de Psicossociologia (EICOS). Essa conformação da turma acabou influenciando no rumo dos debates e atividades, posto que muitas vezes os estudantes apresentavam dúvidas e interesses relativos às suas áreas de formação.

\section{EXPERIÊNCIA DE CAMPO: OS GUARANI NA UFRJ}

Durante os encontros, os conhecimentos apresentados pela mestra e pelo mestre guarani eram continuamente comentados em processos dialogados com a turma e com as professoras não-indígenas, buscando-se, para além da expansão das concepções dos estudantes a respeito das culturas dos povos originários, os pontos de confluência entre os saberes tradicionais e os conhecimentos prévios dos estudantes. As professoras juruás (nãoindígenas), deste modo, atuaram como mediadoras, auxiliando com pequenos comentários e intervenções no sentido de destacar certos pontos e complementar determinadas falas e questões que eram apresentadas nas falas dos mestres indígenas.

Figura 1. Mestre Felix Karaí, Mestra Catarina e professora Samira Lima da Costa durante aula da disciplina Encontro de Saberes

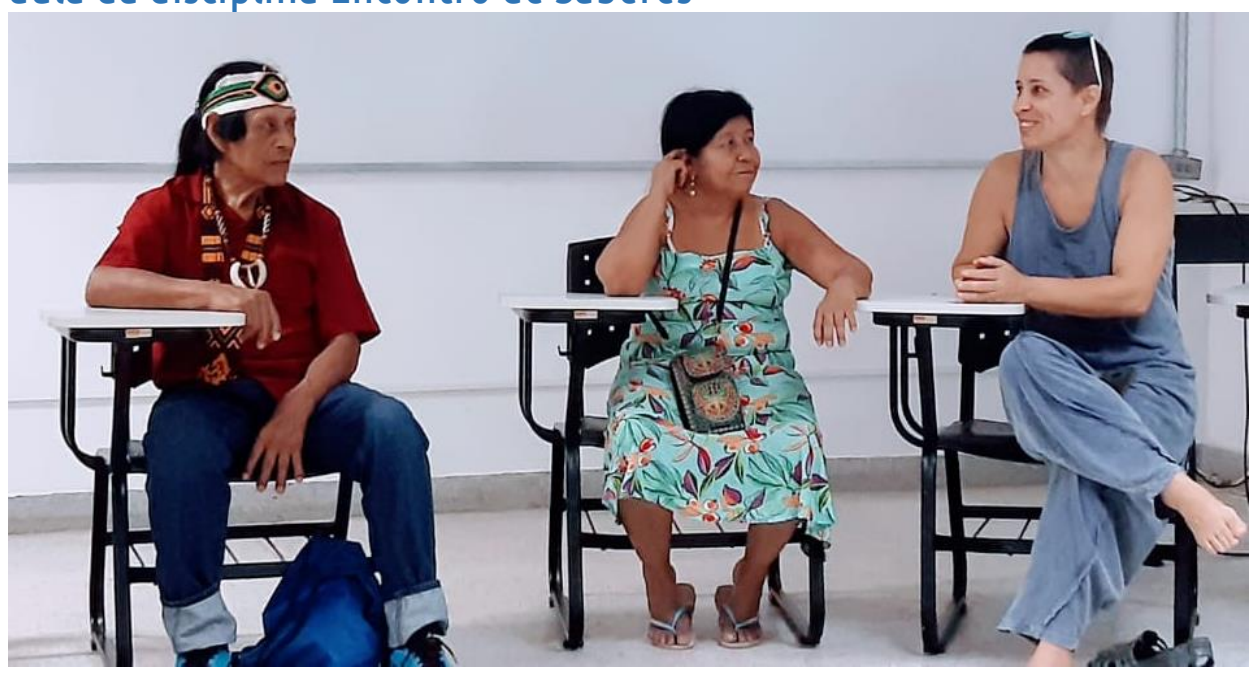

A dinâmica dos encontros permitiu uma construção dialógica, na medida em que os conhecimentos acadêmicos - às vezes divergentes, às vezes convergentes, às vezes complementares - se colocavam diante dos saberes dos mestres. Neste sentido, os 
estudantes traziam questionamentos, teciam comentários, discutiam e apresentavam paralelos a partir de suas próprias experiências, saberes e estudos - sempre tendo como ponto de partida os ensinamentos transmitidos pelos professores indígenas.

As atividades da disciplina ocorreram nas dependências da Faculdade de Medicina, no Fundão, e também contaram com uma visita de imersão à aldeia. Os encontros ocorriam no turno matinal, se iniciando logo cedo com as professoras e estagiários docentes recepcionando os mestres e seus convidados - que chegavam no Campus da Cidade Universitária em transporte da própria UFRJ que, ao final dos encontros, os levava de volta à aldeia em Maricá.

As aulas eram realizadas sempre em círculo, com as carteiras direcionadas aos mestres, que desenvolviam atividades prático-teóricas, sem separação dicotômica. Ao contrário, os temas eram enredados tanto pela narrativa oral dos mestres quanto pela experimentação prática daquilo que estava em foco. Nesta linha:

"A transmissão de conteúdos dá-se a partir da postura de pensar-sentir-fazer. Isso significa que o processo de ensino-aprendizagem não privilegia apenas o campo intelectual, convocando o corpo e os sentidos para participarem no trabalho formativo. Desta maneira, a transmissão de conteúdos ocorre através das técnicas de oralidade, das práticas de observação, da manipulação e confecção de objetos, dos trabalhos de campo, dos ritmos e performances e assim por diante" (INCTI, 2015, p. 8).

As aulas eram marcadas pela experiência da oralidade, na qual as esferas da vida não se separam. Cacique Felix Karaí explica durante uma aula que estes conhecimentos não estão apartados um do outro, sendo que em conjunto são a sustentação do próprio povo Guarani:

Nhanderu, nosso Deus, criou a terra, o mundo, o corpo. Para quê? Eu preciso aprender minha dança, meu canto, minha língua, minha reza para poder me proteger e meu povo sempre; e pra lembrar de Nhanderu. (...) O corpo um dia morre, a alma vai pro céu e um dia volta para outro corpo. O que fica é a sombra. Se a alma não voltar o povo acaba (Cacique Felix Karaí, relato oral. Disciplina Encontro de Saberes na UFRJ, outubro de 2019).

Hampaté Bá (2010) reforça que:

"A tradição oral é a grande escala da vida, e dela recupera e relaciona todos os aspectos. Pode parecer caótica àqueles que não the descortinam o segredo e desconcertar a mentalidade cartesiana acostumada a separar tudo em categorias bem definidas. Dentro da tradição oral, na verdade, o espiritual e o material não estão dissociados. Ao passar do esotérico para o exotérico, a tradição oral consegue colocarse ao alcance dos homens, falar-lhes de acordo com o entendimento humano, revelarse de acordo com as aptidões humanas. Ela é, ao mesmo tempo religião, conhecimento, ciência natural, iniciação à arte, história, divertimento e recreação..." (p. 169).

De um modo geral, os conhecimentos dos mestres são transmitidos pelas vias da tradição oral, sendo repassados através da atuação prática, dos exemplos dos mais velhos e das vivências cotidianas no seio da comunidade, e, portanto, constituem-se como um modelo de ensino-aprendizagem incomum nas academias ocidentais. Neste sentido, fica evidente a necessidade de adequação das universidades, tanto no que diz respeito à oferta de novos 
espaços quanto de reconhecimento de diferentes temporalidades. Ao longo das aulas, verificamos que esse lugar de construir conhecimentos através da prática, o aprender fazendo, nem sempre encontra acolhimento na estrutura da universidade. Assim, quando os mestres e mestras usam instrumentos e cantos, muitas vezes outras pessoas se incomodavam, pois, diziam que o barulho atrapalhava seus estudos. Apesar da escolha de um espaço na UFRJ com entorno arborizado para que os mestres se sentissem mais acolhidos, a estrutura da universidade nos obrigou a realizar os encontros no interior de um prédio, em uma sala de aula convencional que, por suas características, acabaram quebrando um pouco das expectativas dos indígenas. Não obstante, ainda que a disposição da sala fosse circular, muitas vezes esta estrutura não era suficiente para produzir o ambiente considerado pelos mestres como adequado ao que pretendiam ensinar.

Entre os conteúdos abordados é possível destacar exposições acerca da história, da cultura, da língua, das técnicas do artesanato com contas, danças e músicas, bem como outros aspectos da espiritualidade Guarani, incluindo cânticos e rezas. O centro dos debates e das experimentações muitas vezes se ancorava no Nhanderekó. Deste modo, através de ações práticas envolvendo o cantar, o dançar, a confecção de artesanatos e a própria possibilidade de identificar que tais conhecimentos estão totalmente ligados aos aspectos da vida do povo Guarani, foi possível trazer para o debate algumas lições da experiência indígena de conexão com a natureza para o conhecimento acadêmico e a experiência da cidade.

Figura 2. Mestre Felix Karaí auxiliando o professor convidado, Emílio Nolasco de Carvalho (UFF), a pronunciar a letra de música do povo Guarani

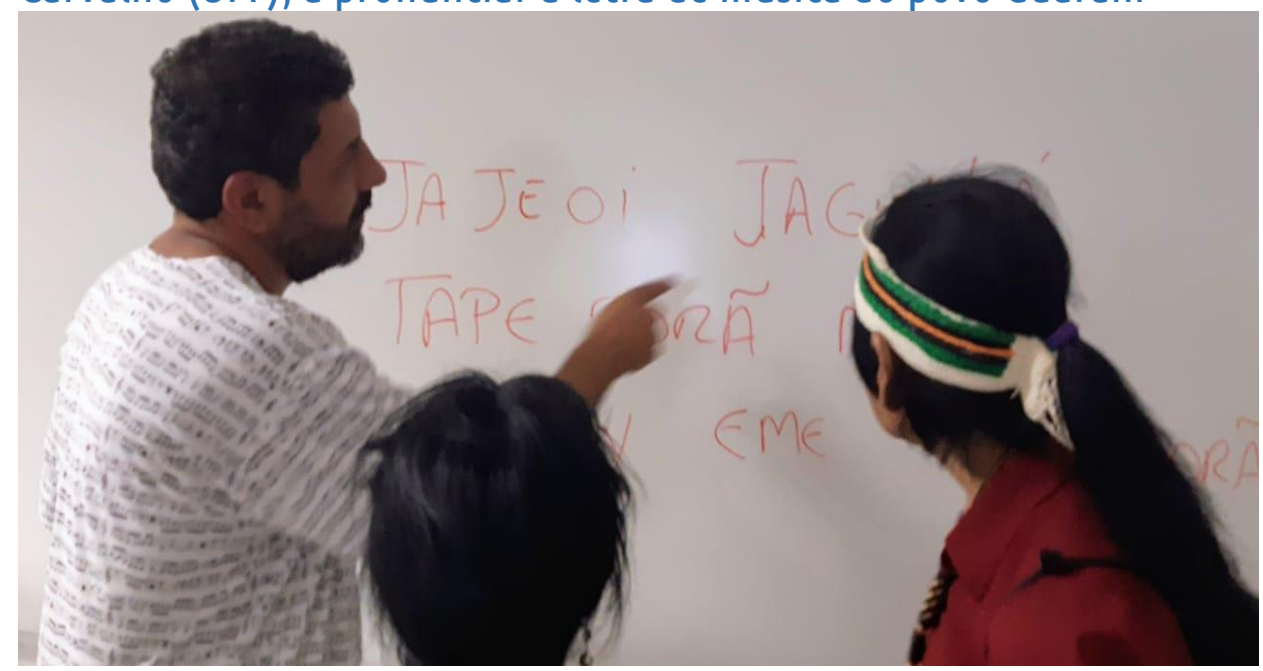

Os encontros produziam na turma um senso de coletivo e um eixo fundado na própria alegria do encontro. Nas aulas dos Encontros de Saberes a turma manifestava alegria frequentemente, mesmo os que nunca tinham vivenciado algo semelhante. A alegria de dançar, a alegria em participar, a alegria de estar ali, de fazer parte daquela experiência, 
estava em todos os presentes - da aldeia e da universidade. Ao contrário da alegria fugaz de um evento espetacularizante - no qual muitas vezes as expressões tradicionais são caricaturadas -, durante as aulas a alegria presente era a de quem, "ao se encontrar com saberes guaranis, se viu encontrando consigo mesma", como foi dito por uma estudante, durante o encerramento. Sobre este resgate da alegria perdida o Xeramõi Felix, em seus encontros com a turma, comentou que os jovens da cidade perderam muito o vínculo com a terra e com a ancestralidade. Como afirma Makota Kidoiale, esse distanciamento, esse desenraizamento produz muito sofrimento para a própria comunidade acadêmica (CARVALHO; KIDOIALE; COSTA, 2020).

Ao longo do semestre, verificamos que quanto mais os estudantes se encontravam com os mestres, mais se libertavam dessa angústia, simplesmente por escutar, por vivenciar, por estar ali. Para garantir este espaço-tempo de estar e de ser, o Encontro de Saberes "propõe pressupostos fundamentais, tais como a indissociabilidade entre teoria e metodologia, bem como entre reflexão e intervenção" (HARTMANN; CARVALHO; SILVA; ABREU, 2019, p. 21).

Nos últimos anos, porém, podemos verificar na própria universidade uma insatisfação crescente com essa estrutura mais endurecida, tanto por parte dos estudantes quanto de docentes e outros trabalhadores. Lembrando Hartmann e colaboradores (2019), identificamos que há uma demanda por:

“...retomar gêneros e práticas das culturas populares, na tentativa de ampliar alguma conexão estética e simbólica do espaço acadêmico, racional e modernista, com o entorno regional e comunitário que abriga cada um dos campi das universidades, com suas especificidades culturais no território nacional" (p. 10).

Durante e após as aulas, havia uma demanda da família guarani por espaços de exposição e venda de artesanatos, o que não se mostrou algo simples de ser feito. A produção do artesanato e sua comercialização faz parte da própria experiência cotidiana no Nhanderekó. Embora as aulas estivessem autorizadas e houvesse ciência institucional acerca do envolvimento dos mestres indígenas nestas atividades, de algum modo o campus parecia ignorar a presença da família, começando pelas dificuldades enfrentadas, incluindo a negação de espaços (públicos) e objeções ao empréstimo de mesas (públicas ou privadas) para a exposição dos objetos de arte. A maior parte dos transeuntes se interessava pelo colorido do artesanato, se aproximava, mas não adquiria muita coisa. Entretanto, as netas do cacique, jovens que ficaram responsáveis pelas vendas, diziam que mesmo assim era bacana ficar ali. Mesmo sem vender, elas viam muitas pessoas diferentes e podiam "mostrar um pouco da aldeia" para elas. O Encontro de Saberes proporciona um olhar maior para o mundo, para os dois mundos.

Com isso entendemos que a experiência da disciplina se esforçou para produzir um encontro epistêmico que se pretende circulante, sem hierarquias ou com hierarquias 
flutuantes e cambiantes, provocando e criando novas experiências sensíveis em várias áreas de estudo. Os novos tempos reivindicam descolonização dos meios universitários e descolonizar, neste caso, não significa inverter lugares de enunciação, mas somar e ampliar; nas palavras de Bispo do Santos (2019), confluir. A intenção de trazer docentes cujas bases e referenciais epistêmicos se constroem originados e orientados em outros âmbitos, fora do eixo acadêmico ocidental moderno da produção de conhecimento - masculino, branco, cristão, europeu - é colocar em encontro e, talvez, em diálogo esses dois ambientes, dois universos. É deste modo que Sandra Benites, ao sair da aldeia para entrar na academia, reforça em sua fala "eu estou no entre", o que potencializa seu discurso e se faz necessário para criar e atuar em "micropolíticas de resistência ${ }^{13 "}$, reconhecendo a memória como instrumento importante para combater o medo e defender o território, o corpo-território (BENITES, 2019).

\section{EXPERIÊNCIAS DE CAMPO: JURUÁSNA ALDEIA}

Buscando oportunizar aos participantes da disciplina um pouco da experiência da aldeia, a mestra e o mestre Guarani Mbya convidaram a turma para uma aula de campo na Tekoã Ara Howy (Aldeia Céu Azul), em Maricá (RJ).

A aldeia Tekoã Ara Howy se localiza em uma região isolada do município de Maricá, em meio à mata do Parque Estadual Serra da Tiririca, uma das mais antigas unidades de conservação do estado do Rio de Janeiro ${ }^{14}$. Baptista, Benites e Sánchez (2017) destacam que "a tekoa Ara Howy foi fundada em 2013 e está na zona de amortecimento do Parque Estadual da Serra da Tiririca o que traz implicações ambientais acerca do manejo da área" (p. 2). Ou seja, o fato de estarem no interior do parque impõe uma série de limitações às atividades tradicionais da cultura guarani, restringindo práticas como agricultura, caça e coleta.

Ainda assim, eles se adaptaram à região na medida do possível, embora apontem algumas dificuldades como a falta de um rio para a realização de rituais, a impossibilidade de cultivarem seus próprios alimentos e a luta para a manutenção de certas tradições. Apesar disso, a aldeia está ali há sete anos e a ida da primeira turma da disciplina Encontro de Saberes da UFRJ a este território foi justamente na ocasião de celebração do aniversário da aldeia.

Para chegar à aldeia deve-se subir uma trilha pelo morro, passando pela escola intercultural indígena e seguindo pela mata até alcançar um terreno mais alto, onde existem algumas casas entre as árvores, bem como um espaço central. Logo na chegada se percebe o

\footnotetext{
${ }^{13}$ Título do evento realizado na Casa da Ciência, no qual Sandra Benites fez as falas aqui referidas.

${ }^{14}$ Criado pela Lei Estadual n 1.901, de 29 de novembro de 1991.
} 
contraste das experiências: ao contrário do ambiente da universidade - marcado pela artificialidade dos elementos prediais, com corredores planos e de concreto, salas quadradas, quadros, carteiras, portas e janelas -, a aldeia transparece um ambiente orgânico, natural, com espaços amplos e abertos, muito verde e chão de terra, e cuja existência é integrada de maneira muito forte com a natureza.

Figura 3. Fotografia da festa na aldeia

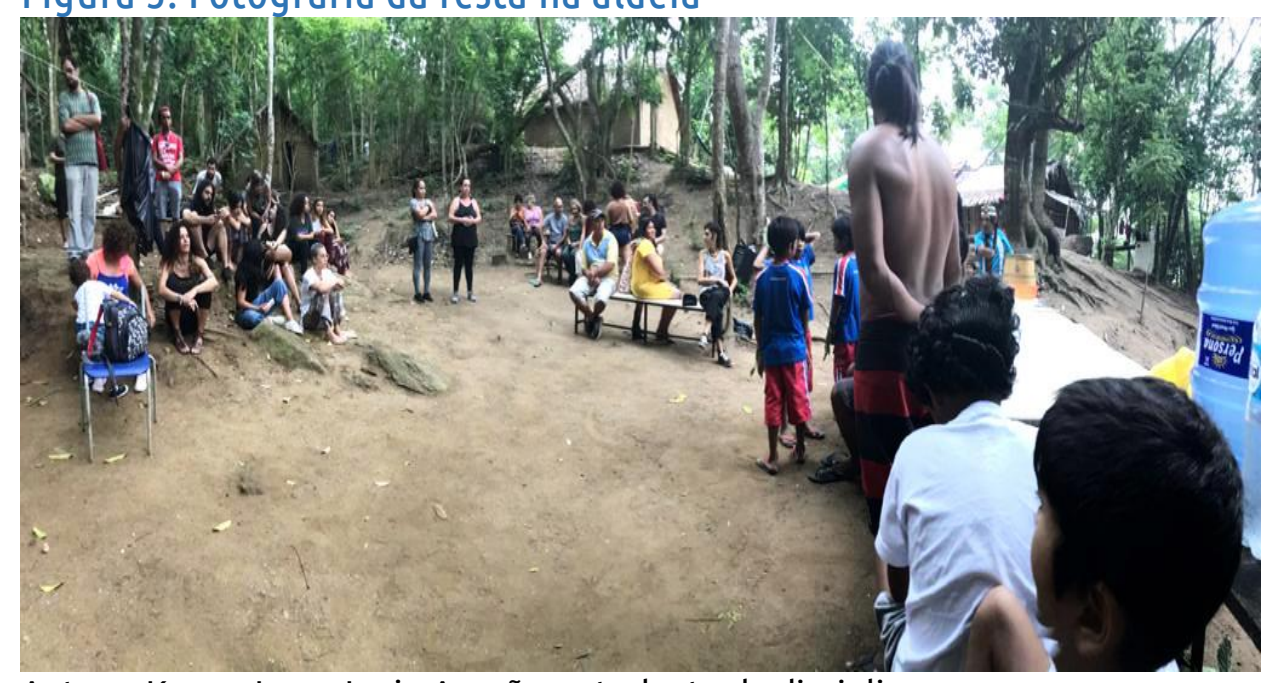

Autora: Karen Joyce Lyrio Aragão, estudante da disciplina.

Sobre essa distinção entre os espaços, recordamos uma questão muito importante para a perspectiva guarani, a conexão intrínseca entre espaço, modo de vida e língua, destacando que a tradução é um conhecimento, cada um tem a sua forma de traduzir, mas nem todas as coisas são traduzíveis em determinados lugares. Com isso entendemos que determinados elementos da cultura guarani são intraduzíveis em determinados espaços, como é o caso do espaço universitário. Isso por sua vez nos leva a compreender a importância de o Encontro de Saberes se estabelecer enquanto um movimento de duplo sentido, tanto na entrada dos mestres na universidade, como da universidade indo até os territórios tradicionais.

Durante a festividade a turma foi apresentada a músicas e danças com uma apresentação realizada pelas crianças e uma exposição dos artesanatos, tendo a possibilidade de interagir diretamente com os artesãos. Foram servidas comidas comuns à alimentação na aldeia, como o peixe assado em folha de bananeira, o xipán ${ }^{15}$ e frutas. Uma experiência de imersão na cultura que revela uma vivência para além do que os muros da academia podem oferecer.

\footnotetext{
${ }^{15}$ Alimento tradicional indígena que consiste em uma massa feita com farinha e frita.
} 
Figura 4. Ilustração da festa na aldeia.

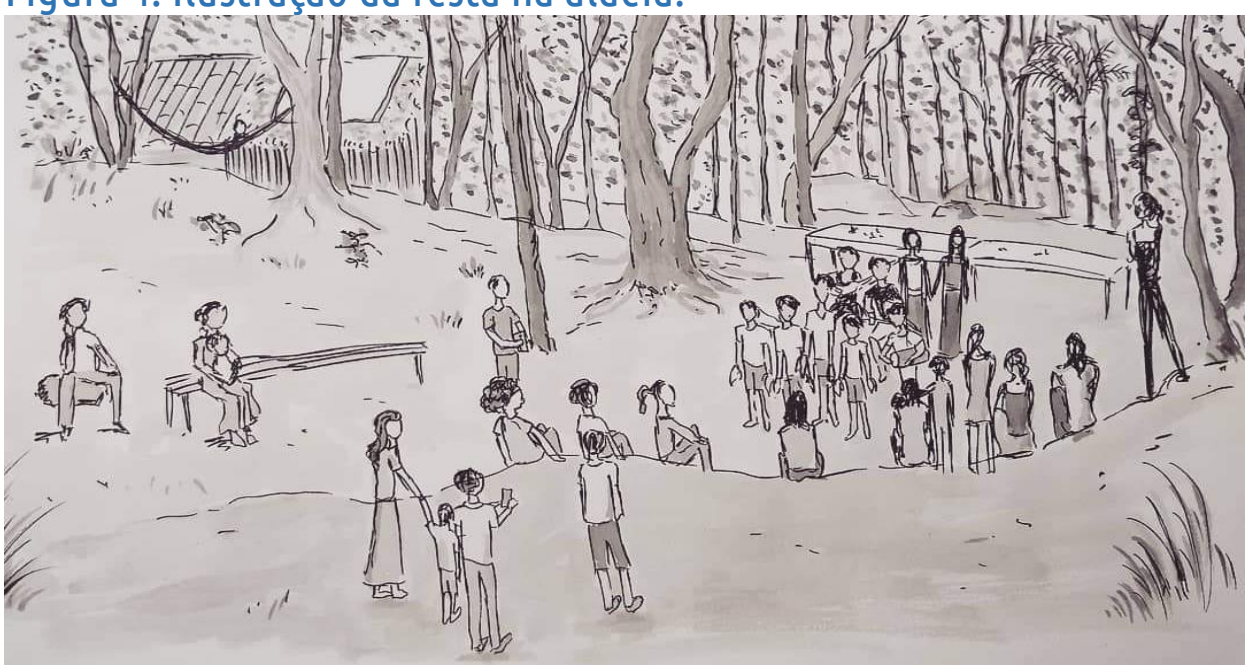

Autor: Daniel Renaud Camargo, estudante da disciplina.

\section{REFLEXÕES SOBRE A DISCIPLINA ENCONTRO DE SABERES NA UFRJ: APRENDIZADOS SOBRE AS CONFLUÊNCIAS E SOBRE NOSSAS LIMITAÇÕES}

A presença do mestre e da mestra guarani no ambiente universitário nos direciona para a reflexão a respeito da necessidade de entendermos os conhecimentos tradicionais para além dos territórios físicos, também abrangendo os territórios epistêmicos. Ainda que a sala de aula não fosse um ambiente "aldeado", por meio dos cantos e da redistribuição dos participantes em círculos, sentados no chão, os mestres constituíam a cena do encontro num modelo que consideravam mais adequado ao conhecimento que pretendiam apresentar. Nas avaliações, a disposição da sala e a ambientação a partir dos cantos foram consideradas pontos forte da disciplina que, entre outras sensações, produziam o deslocamento epistêmico da turma, para outros lugares do saber.

Em alguns momentos, a mestra e o mestre Guarani abordaram como seu povo vem sofrendo com as diversas opressões e conflitos, presentes em uma sociedade que não foi capaz de superar a estrutura legada por um agressivo processo de colonização. Nestes momentos, nos revelaram um outro ponto de vista acerca da história dos povos originários, uma visão que, ao contrário da narrativa hegemônica, nos aponta uma trajetória de luta, resistência e orientação espiritual a partir das vozes daqueles que as vivenciaram. Esta discussão nos remonta ao debate estabelecido pela indiana Gayatri Spivak (2010) em sua clássica obra "Pode o Subalterno Falar?" A autora, apoiada nos estudos pós-coloniais, denuncia a violência epistêmica existente nas invisibilizações promovidas pelos processos de colonização e subalternização, pontuando de maneira incisiva que, apesar das tentativas de apagamento das vozes destes sujeitos, estes não só podem falar, como falam e são capazes de nos ensinar muito do que ficou submerso pela imposição da versão da história que nos é contada pelos grupos dominantes. 
Nesta mesma linha, podemos também perceber que no Brasil sofremos o que a escritora nigeriana Chimamanda Ngozi Adichie (2019) chama de "o perigo da história única", quando apenas uma perspectiva da história é considerada, em detrimento das múltiplas narrativas em disputa. A construção eurocêntrica da história do Brasil se tornou, assim, a história oficial, essa "história única do Brasil" que se sobrepôs e invisibilizou as histórias de múltiplas etnias e povos que continuam resistindo.

Nas palavras do autor e mestre quilombola Antônio Bispo:

"Uma [história] bastante exótica que aprendi no meu tempo de escola é a de que os portugueses chegaram no Brasil porque se perderam no caminho das Índias (...) essa versão ganha consistência na denominação que foi dada aos povos originários por eles aqui encontrados. Esses povos até hoje são chamados de "índios", exatamente porque os portugueses pensavam ter chegado as "índias"(...). Mais estranho ainda é que os povos aqui encontrados como, por exemplo, os povos de língua tupi que chamavam esta terra de Pindorama (Terra das Palmeiras), continuam sendo chamados de índios. Como sabemos, esses povos possuem várias autodenominações. Os colonizadores, ao substituírem as diversas autodenominações desses povos, impondo-os uma denominação generalizada, estavam tentando quebrar suas identidades com o intuito de os coisificar/desumanizar" (SANTOS, 2019, p.20).

A posição de Bispo dos Santos (2019) se aproxima da concepção de Chimamanda Adiche (2019) que, ao nos alertar sobre o perigo de uma "história única", nos remete diretamente à edificação da universidade, que reproduz essa lógica hegemônica e cuja história também é única - ou tem sido até então. Na universidade ocidentalizada aprendemos, entre outras coisas, a coisificardesumanizar para analisar, a generalizar; e, sobretudo, aprendemos a dar nome as coisas.

Antônio Bispo dos Santos (2019) lembra ainda que "nem tudo que se ajunta, se mistura", quando ele nos explica sobre a lei da confluência - lei que rege a relação de convivência entre os elementos da natureza. Esta relação se estabelece através da lógica cosmovisiva politeísta que se dá pelo respeito, a organicidade e biointeracão com os elementos da natureza. Assim, ele propõe transformar "as divergências (entre culturas) em diversidades, e na diversidade atingirmos a confluência de todas as nossas experiências" (SANTOS, 2019, p.69).

Bispo dos Santos (2019) nos conduz a considerar duas formas de saberes: os orgânicos, representados pelos saberes dos povos tradicionais, que expressam a postura da biointeração. Estes também são entendidos como os saberes populares ou saberes da terra, que são produzidos a partir dos processos interativos dos povos tradicionais e comunidades locais com a natureza. Por outro lado, se encontram os saberes sintéticos, que seriam justamente aqueles desenvolvidos na assepsia promovida e estimulada pelas academias norte-centradas. Em contraposição, 
entendemos que as trajetórias acadêmicas podem, em muitos casos, convergir objetivos e somar conhecimentos com povos tradicionais. Oralidade e escrita podem se compor, muitas vezes, uma como suporte da outra. Portanto, entendemos os saberes acadêmicos e os saberes tradicionais como saberes heterogêneos, que apesar de poderem ser "ajuntados", não necessariamente se "misturam", gerando, deste modo, diferentes cosmovisões que podem ou não atuar em complementariedade. Atualmente, entretanto, é preciso admitir que a universidade carece do conhecimento tradicional, reconhecido como tal.

Lembrando Sandra Benites "a academia é como uma violência, mas eu precisava sair [da aldeia] para falar" (BENITES, 2019). E é precisamente neste sentido - da necessidade de falar - que o Encontro de Saberes vem abrindo e produzindo espaços, entradas e encontros. Há algo a se dizer, e as confluências podem produzir enunciações polifônicas.

Este ponto representa uma diferença, no encontro entre mundos tão distintos. A hiper-valorização do lugar da escrita a coloca em destaque na universidade, em detrimento do que seria a experiência. A escrita acaba por se fazer parecer o principal elemento da produção de conhecimento, ao mesmo tempo garantidor e testemunho do aprendizado, muitas vezes suspendendo a própria oportunidade da experiência para redigi-las. Tal fator leva, por exemplo, alguns e algumas estudantes a manterem demasiada preocupação em registrar e anotar suas experiências de aprendizado, mesmo em uma disciplina como esta, cujos mestres e mestras afirmam a fala como principal meio. A este respeito, certa vez Chogyam Trumgpa, mestre do saber vajrayana tibetano, em seu primeiro contato com a universidade ocidental, perguntou: "Por que vocês escrevem tanto? Por que usam o caderno? Não confiam em suas mentes?"16.

Na experiência da disciplina, o aprendizado - e não necessariamente a escrita -, ao ganhar centralidade, marca os muitos possíveis, que se apresentam de modos diferentes nas participações de estudantes. Na avaliação, a busca por meios de expressão do que se experimentou, se elaborou e se aprendeu gera muitas linguagens e muitos esforços de se fazer entender. A escrita se mistura com a oralidade, e no momento de dizer ao mestre e à mestra guarani o que aprenderam,

\footnotetext{
${ }^{16}$ DEMETAKAS, OHANNA Louca Sabedoria - A vida e os tempos de Chögyam Trungpa Rinpoche. Produzido e dirigido por JOHANNA DEMETAKAS produzido por LISA LEEMAN (Filme). www.crazywisdomthemovie.com @ 2011 Crazy Wisdom Productions
} 
outros traços da narratividade se manifestam. Fotografias, artesanatos, poesias, cantos e danças ganham lugar de linguagem, se misturam nas trocas entre professoras, mestres e mestras, estudantes, netas.

Paulo Freire (1986, p. 80) declara que é preciso perseguir a esperança de educadores/as e educandos/as poderem "aprender, ensinar, inquietar, produzir, e juntos igualmente resistir aos obstáculos à nossa alegria". Consideramos, portanto, o encontro - e a alegria do encontro - como elemento insubstituível para estes processos de aprendizados e produções interepistêmicas. Reconhecemos o grande esforço que os mestres e mestras do Encontro de Saberes fazem, ao saírem de seus universos de referência - espacial, temporal, relacional e linguístico - para virem ao nosso encontro. Porém, afirmam com leveza e alegria que o Nhanderekó vem junto. Ainda que a universidade não pareça preparada para o Encontro de Saberes, a própria disciplina abre suas trilhas, os próprios mestres e mestras constroem o ambiente de que precisam para que as aulas aconteçam.

Deste modo, os mestres e mestras prescindem de interpretação ou tradução. A presença de professoras acadêmicas propicia encontros entre professores/as - de lá e de cá - mas não se propõe a traduzi-los. Como lembram Hartmann e colaboradores (2019), “...os mestres e mestras ensinam os seus gêneros e rituais com seus métodos próprios de transmissão, sem a necessidade da tradução que até agora era exercitada exclusivamente pela nossa classe de docentes acadêmicos" (p. 24).

Assim, a disciplina produz encontros entre saberes, entre mundos, entre cosmovisões, entre corpos - entre docentes acadêmicos e guaranis, entre aprendizes acadêmicos e guaranis. E produz a alegria do encontro, ao que Benites complementa "não podemos perder a alegria e a coragem... Pois a luta se faz sorrindo" (2019, Casa da Ciência, UFRJ).

\section{CONSIDERAÇÕES FINAIS}

Ao falarmos sobre modos de funcionamento social na cidade, recorremos rapidamente a inúmeros referenciais. Não precisamos abrir mão destes nossos referenciais, nem do que somos ou sabemos. Ao contrário, o convite está em abrir espaços, caminhar para ampliar, somar - não diminuir. A proposta é sustentar encontros, confluências ou, como diria Paulo Freire, experiências de amorosidade: um exercício profundo de existir e defender toda existência, co-existir. Não nos caberia, então, lutar pela extinção de certos saberes - por considerarmos menores - ainda que fundados em certos centrismos. Neste sentido, nos 
caberia, antes, buscar o que não temos, o que não sabemos, ampliar nossos saberes com os saberes do outro. No caso desta disciplina, nos caberia conhecer, para além dos modos de viver na cidade, também os modos de viver Guarani - o Nhanderekó.

As universidades ocidentais historicamente se destinaram a formar escribas, quer dizer, o cerne de suas ações esteve focado na escrita, na leitura e produção de textos, na codificação e documentação da realidade a partir de monografias, dissertações, teses, artigos, livros etc. Em contrapartida, os povos originários assumem a centralidade da oralidade como forma de transmissão de seus conhecimentos, histórias e tradições. Não abrem mão de aprender a língua escrita, mas não perdem o eixo da oralidade.

Esta oportunidade de receber mestres indígenas como professores convidados ministrando aulas na universidade semeia na comunidade acadêmica um estranhamento, mas também um tipo de revolução na construção do conhecimento até então fundado na ciência ocidental moderna de modo hegemônico, nomeado como "oficial". A esse respeito, uma das estudantes da disciplina comentou: é como encontrar o que nunca esteve separado, senão desencontrado.

Assim, a semente que fiou o cordão indígena se espalha pela UFRJ e traz um colorido diferente para os corredores da academia, com a possibilidade de conhecer histórias que a História não conta. Ela também possibilita aos professores, estudantes e ilustres visitantes vislumbrarem uma educação de esperança.

Com isso, entendemos que a disciplina Encontro de Saberes nos desvela uma série de pontos chaves para a produção de pontes de confluência entre diferentes epistemologias, culturas e modos de ser. Porém, para isso se dar de forma efetiva a universidade, enquanto instituição produtora de conhecimentos, para além de abrir seus espaços para a entrada destes corpos detentores e produtores de saberes outros precisa também se adaptar a esta novidade, adequando também seus espaços e tempos para permitir caminhos alternativos de ensino-aprendizagem. Pontuamos também a importância de um movimento duplo, tanto dos mestres adentrando as universidades, como das universidades se dirigindo aos territórios tradicionais, levando em conta a intraduzibilidade de certos saberes em determinados espaços.

\section{REFERÊNCIAS}

ADICHIE, Chimamanda Ngozi. 0 Perigo de uma História Única (tradução de Julian Romeu). $1^{\text {a }}$ ed, São Paulo: Companhia das Letras, 2019.

BAPTISTA, Clara dos Santos; BENITES, Sandra; SÁNCHEZ, Celso. Interculturalidade e Educação Ambiental: Possibilidades e Desafios com a Cultura Guarani Mbya. Anais do Encontro de Pesquisa em Educação Ambiental (IX EPEA), Juiz de Fora, MG, 2017. p. 1-16. 
BENITES, Sandra. Viver na língua Guarani Nhandewa (Mulher falando). Dissertação de mestrado Programa de Pós-Graduação em Antropologia Social, Museu Nacional, Rio de Janeiro, 2018.

BENITES, Sandra. Sandra Benites, apresentação oral. Evento: Micropolíticas da resistência - II Seminário do Laboratório Memórias, territórios e Ocupações: rastros sensíveis. Casa da Ciência, UFRJ. Rio de Janeiro, RJ. 2019.

BRASIL, Lei de Ações Afirmativas. Diário Oficial da União de 11 de março de 2008, Seção 1.

CARVALHO, José Jorge de; ÁGUAS, Carla. Encontro de Saberes: Um desafio Teórico, Político e Epistemológico. In: SANTOS, Boaventura de Sousa; CUNHA, Teresa (eds). Actas do Colóquio Internacional Epistemologias do Sul: aprendizagens globais Sul-Sul, Sul-Norte e Norte-Sul, vol 1, Democratizar a Democracia, Junho, 2015. p. 1017-1027.

CARVALHO, José Jorge de; KIDOIALE, Makota; CARVALHO, Emilio Nolasco de: COSTA, Samira Lima da. Sofrimento psíquico na universidade, psicossociologia e Encontro de saberes. Revista Sociedade e Estado, v. 35, n. 1, p. 135-162, 2020.

COSTA, Samira Lima da; CARVALHO, José Jorge de. Processos de transmissão: 0 ensino universitário e o encontro com mestras e mestres dos saberes tradicionais. In: MONTEIRO, Ana Cláudia Lima. Processos psicológicos, perspectivas situadas (No prelo). EdUFF, 2020.

FREIRE, Paulo. Pedagogia da Autonomia, saberes necessários à prática educativa. São Paulo: Paz e Terra, 1986.

FREIRE, Paulo. Pedagogia do Oprimido. 17ª ed, Rio de Janeiro, Paz \& Terra, 1987.

INSTITUTO DE INCLUSÃO NO ENSINO SUPERIOR E NA PESQUISA - INCTI. Encontro de saberes: bases para um diálogo interepistêmico. Brasília, DF: INCTI, 2015.

HAMPATÉ BÁ, A. A Tradição Viva. In: KI-ZERBO, Joseph (ed). História Geral da África, I: Metodologia e Pré-História da África. 2ed revisada, UNESCO, Brasília, 2010. p. 167-212.

HARTMANN, Luciana; CARVALHO, José Jorge; SILVA, Renata de Lima; ABREU, Joana. Tradição e Tradução de Saberes Performáticos nas Universidades Brasileiras. Repertório, Salvador, v. 22, n. 33, p. 8-30, 2019.

RIO DE JANEIRO. Lei estadual n 1901, de 29 de novembro de 1991. Dispõe sobre a criação do Parque Estadual da Serra da Tiririca e dá outras providências. 1991. Disponível em: http://alerjln1.alerj.rj.gov.br/CONTLEI.NSF/bff0b82192929c2303256bc30052cb1c/0a9eb98540ee62b f032565210079711b?OpenDocument

SANTOS, Antônio Bispo dos. Colonização, Quilombos: modos e significações. 2 ed revisada e amplicada. Publicação Instituto Nacional de Ciência e Tecnologia (INCT), Universidade de Brasília (UNB), Programa Institutos Nacionais de Ciência e Tecnologia, Ministério da Ciência, Tecnologia e Inovação (MCTI), Brasília, Março de 2019.

SPIVAK, Gayatri Chakravortry. Pode o Subalterno Falar? (tradução de Sandra Regina Goulart Almeida; Marcos Pereira Feitosa; André Pereira). 1 ed, Editora UFMG: Belo Horizonte, 2010. 
Costa, Gabriel, Camargo, Aragão e Benites

Recebido em 2 de setembro de 2020. Aprovado em 1 de fevereiro de 2021. 